\title{
CONSUMO: UM OLHAR PARA A ALIMENTAÇÃO
}

\section{Consumption: a look for food}

Amanda Costa Reis de Siqueira ${ }^{1}$

\section{Resumo}

Este artigo tem como objetivo desvendar como o modelo de restaurante a quilo se tornou um "espaço social alimentar" onde se revelam representações de valores da cultura brasileira e traços da nossa identidade social.

Palavras-chave: consumo alimentar, hábitos alimentares, simbologia do poder da comida.

\begin{abstract}
This article aims to uncover how the model of a kilo restaurant has become a "food social space" where they are representations of figures of Brazilian culture and features of our social identity.
\end{abstract}

Keywords: food intake, dietary habits, symbolism of the power of food.

\section{Resumen}

Ese documento tiene el objetivo de desentrañar como los restaurantes por kilo se convertieron en un espacio social donde los alimentos ponen de manifiesto las representaciones de los valores de la cultura brasileña y huellas de nuestra identidad social.

Palabras-clave: la ingesta de alimentos, hábitos alimentícios, el simbolismo de la potencia de los alimentos.

\section{INTRODUÇÃO}

\footnotetext{
1 Jornalista e Mestre em Sociologia, Política e Cultura pela PUC-RIO, E-mail: amandacostareis@gmail.com, Telefones: (21) 2539-6415/9254-9741
} 
Quando falamos de consumo, podemos navegar pelos mais variados temas: moda, comportamento, economia, etc. Ao criar um olhar interessado para algum desses tópicos é possível perceber inúmeras características sociais.

Podemos olhar o nosso cotidiano e perceber ações, trajes, mídias exalando modos de consumo. Pessoas usando seu dia-a-dia para expor objetos, formas de agir, padrões culturais, enfim, diversas formas de se mostrar e se comportar que acabam por revelar mais do que atitudes e aparências.

Tomo como exemplo a alimentação, já que, a partir dela, construí meu tema de dissertação de Mestrado. Ao realizar um estudo antropológico sobre alimentação no Brasil, escolhi como objeto de estudo os restaurantes a quilo do centro do Rio de Janeiro. É através dele que tentarei expor alguns argumentos sobre como o consumo é capaz de revelar traços característicos de nossa sociedade.

\section{PRATO PRINCIPAL}

Para explicitar algumas das características destes espaços vamos ao que denominarei de "Prato Principal". Ou seja, uma interpretação das principais palavras que surgiram durante entrevistas com clientes, funcionários, gerentes e donos dos estabelecimentos. São elas: tempo, centro da cidade e hora do almoço.

O tempo como palavra mais usada pelos entrevistados, de ambos os sexos e das mais diferentes faixas etárias, aponta para sua representação enquanto algo quase concreto, mas que ao mesmo tempo está a todo tempo escapando e tendo que ser aproveitado.

Como palavra cujas interpretações o colocam próximas a algo palpável, quase concreto, encontra-se o tempo tão precioso aos entrevistados. Aquela uma hora que normalmente é disponibilizada para o almoço se transforma num horário condensado, que ganha forma. Por isso, quando todos saem de seus escritórios, salas comerciais e demais espaços laborais com o estabelecimento pré-determinado do tempo a se gastar, os segundos, minutos, se tornam material contável. 
Dessa forma, há uma hora do dia que se converte em algo mais "concreto", já que a pré-determinação do horário a se gastar durante a refeição da hora do almoço confere ao trabalhador sentido de prazo, de maior percepção de um período com a fixação de início e fim. Essa "condensação do tempo" normalmente é encontrada no horário do meio-dia às 13 h. Este é, não por coincidência, também o período de maior movimentação nos restaurantes do centro da cidade do Rio de Janeiro.

É "no horário mais movimentado, de meio-dia às $13 \mathrm{~h}$ " que se pode notar a dinâmica dos restaurantes. Ela se dá para conseguir atender rapidamente todos aqueles que desejam disponibilizar apenas parte de sua uma hora de intervalo para estarem naquele local

Dessa forma, ainda que estabelecida a hora do almoço, sempre havia entre os entrevistados a justificativa de que seu tempo para almoçar deveria ser prático, sem a necessidade de que se tomasse uma hora para fazê-lo. Aqui se estabelece esta vertente do tempo, que deve ser aproveitado para realizar a refeição como também para outros afazeres.

Como a "sociabilidade urbana" introjeta a ideia do "perder tempo", que significa estar em descompasso com a ordem das coisas em um "conjunto de atividades entre elas: morar, vestir, fazer compras, trabalhar, passear" estes momentos do dia estão sempre com pessoas em movimento, preocupadas com a pressa (Ortiz 1994:82,83). Não seria diferente com a hora do almoço no centro urbano, que está envolta nesta mesma lógica e poderia estar inclusa neste "conjunto de atividades" acima enumerado.

A dinâmica do ato de comer e sair nestes restaurantes levava em torno de 20 minutos, com exceção de algumas mesas animadas, normalmente formadas por grandes grupos, onde as pessoas levavam no máximo 30 minutos para se retirarem. Mas, de maneira geral, em 40 minutos, todos os clientes já haviam sido substituídos por novos clientes. Este é o exemplo da rotatividade, do movimento constante já que a rapidez de entrada e saída de pessoas era incessante.

Sob esta agilidade, está o controle do relógio, onde se confere todo momento que horas são, numa regulação constante do tempo que se deve permanecer no local. Nesse sentido, o relógio expressa a uniformização de um tempo "vazio", que foi quantificado de maneira a determinar zonas do dia, como a jornada de trabalho (Giddens 1991). Torna-se quase palpável a sensação de tempo, pois se cria uma intenção de uso do local a partir de minutos marcados, contados. Eles determinam as atividades; tem-se a 
imaginação de um cronômetro correndo e inúmeras tarefas a serem cumpridas num período determinado.

Durante meu trabalho de campo, foi possível presenciar que nenhum cliente passava esta uma hora de almoço a que tinha direito à mesa. Para comprovar isto, eu passava horas dentro dos restaurantes e sempre recebia olhares de estranheza, como se todos se questionassem sobre o porquê de eu estar tanto tempo ali. Estava eu, de certa forma, "denegrindo a lógica" do ambiente que deixava implícitas ações como comer em um período curto, sem que se tomasse com isso todo o horário reservado ao almoço.

As pessoas, em teoria, poderiam ficar o quanto quisessem no local, mas a estrutura deste é montada a lhe conferir movimentação. O serviço é realizado de maneira a que se sirva rapidamente da comida, que se pese, consuma e se pague de modo muito ágil.

É pegar um prato para se servir, eleger o que colocar nele, comer e pagar. Estas ações estão tão introjetadas, que são capazes de produzir esta dinâmica de rotatividade que promovem "discretamente" o uso e, por que não, a agilidade do local.

Não há nenhuma regra imposta que faça com que as pessoas utilizem o local assim, mas a forma como a comida, as mesas e os caixas para pagamento estão dispostos constrói um espaço aberto a este tipo de rotatividade permanente.

\subsection{Relativizando...}

Ainda que haja busca pelo aproveitamento total de algo - o "tempo" - que está mais no trânsito entre o concreto e o abstrato que especificamente num e noutro, se enfatiza o fato de se estar comendo comida de verdade. Ou seja, mesmo com a tentativa de aproveitar ao máximo o tempo disponível neste intervalo do trabalho, que é a hora do almoço, se está num lugar que oferece comida e não alimento para "tapear o estômago" e "sem sustância".

Apesar da velocidade do comer, estes restaurantes não são considerados fastfoods simplesmente; são locais onde se come "comida de verdade", refeições que realmente "sustentam" as pessoas.

Quando os clientes revelam que encontram nestes locais "comida de verdade", apontam para a manutenção de oferta de pratos que percebem como comida, ou seja, como algo que produz interação, sentimento de reconhecimento e de identificação entre os pratos e a composição da cultura brasileira. 
Em outros estabelecimentos que possuem a mesma agilidade no servir de uma refeição, falta este sentimento da comida; o que se serve é apenas alimento, algo que deve ser servido a qualquer comedor e não é visto como prato capaz de manter energia suficiente para todo um dia de trabalho (Poulain 2006).

É a opção da rapidez aliada a costumes que já estavam bem estabelecidos entre nós nos rituais de refeição que fazem destes restaurantes uma fórmula contagiante, que tomou as ruas do centro urbano do Rio de Janeiro.

O molho desta mistura do Prato Principal é o centro da cidade. Capaz de envolver as várias possibilidades de uso do termo "tempo", é ele quem ajuda na significação do mesmo, pois é o local de trabalho de grande parte da população carioca. É neste ambiente onde a circulação de trabalhadores é constante que estão localizados os restaurantes pesquisados e onde o espaço de ruas e avenidas pode revelar muito sobre o ritual da alimentação que envolve a hora do almoço durante os dias úteis da semana.

Quando o assunto é o centro da cidade, a importância desta localidade vai além de ser simplesmente o local geográfico onde se instalaram estes estabelecimentos. Lá se está diretamente associado ao mundo do trabalho, pois, distante de nossas casas e para onde vamos quando saímos para trabalhar, temos com ele uma relação distinta, que não encontramos quando estamos no mundo de nossas casas. Estamos na rua, local onde todos circulam, onde esbarramos com "todo tipo de gente", lugar que não é de uso exclusivo nosso e onde não escolhemos quem será convidado.

Esta lógica do horário do almoço nos restaurantes a quilo situa-se numa relação de tempo-espaço que perpassa a lógica interna destes estabelecimentos e alcança a dinâmica do movimento do centro da cidade.

A localização e as especificidades da cidade carioca fizeram por transformar os restaurantes que atendem o público da hora do almoço num local integrador de características universais do self-service (auto-serviço) com temas da "criatividade brasileira", como as misturas de comidas que normalmente não são consumidas em conjunto.

Em se tratando da hora do almoço nos restaurantes a quilo, pode-se dizer que ela revela um pouco mais do nosso comportamento fora de casa. Almoçamos em trajes de trabalho; nos preocupamos com o tempo que temos para comer e com outros compromissos; compartilhamos da refeição com pessoas com as quais mantemos relações de formalidade, enfim, encontramos elementos que reforçam a relação com o ambiente da rua. 
O tempo livre do almoço não é visto como uma refeição que segue um ritual que dura exatamente uma hora disponível a trabalhadores e estudantes. Pelo contrário, esta nova modalidade de restaurante traduz essa nova relação das pessoas com o espaço de tempo livre que conseguem no intervalo do trabalho.

A exemplo do uso do tempo da hora do almoço para outras tarefas que não apenas a refeição, uma das entrevistadas revela que "mesmo com uma hora para almoçar, nunca gasto este tempo todo apenas para comer. Mesmo quando não preciso resolver alguma coisa importante, vou a uma loja, a uma livraria”.

É preciso destacar que a hora do almoço tem características que estão além da alimentação. Neste horário, no meio de um dia de trabalho, como se costuma dizer, é comum que se resolvam outros tipos de compromisso.

As filas dos bancos lotam de pessoas pagando suas contas, as academias de ginástica recebem os mais preocupados com o corpo, os consultórios recebem pacientes, as lojas recebem consumidores, as "casas de massagem" também recebem seus clientes. Ou seja, a hora do almoço virou um horário para os mais variados tipos de tarefas.

As "casas de massagem" são locais onde se oferecem serviços sexuais. No centro da cidade, elas existem em grande quantidade e, inclusive, ocupam salas de edifícios comerciais. Estes locais recebem grande movimento justamente no horário de almoço e, segundo um colega de Mestrado que trabalha em uma empresa também no Centro, seus colegas se referem a uma ida a este local como "fazer um lanche rápido".

Isso não quer dizer que tenha se perdido toda a ligação do almoço com rituais que envolvem uma refeição; pelo contrário, estes restaurantes servem de exemplo para uma dinâmica onde o protagonismo da refeição esbarra em outros personagens tão importantes quanto aquele.

Em outras palavras, os restaurantes do tipo a quilo possibilitam que trabalhadores do centro da cidade dividam seu espaço da refeição com outros afazeres. O que é chamado de hora do almoço não se destina apenas à ação de comer; também é neste intervalo que outras tarefas do cotidiano são resolvidas.

A valorização do curto espaço de tempo, onde se deve realizar o maior número de atividades possível, a espacialidade do centro da cidade que comporta locais para que esta dinâmica de aproveitamento do tempo seja cumprida e um horário estipulado, onde se sente o cronômetro correr, fazem os restaurantes a quilo característicos desta lógica. 
Afinal, eles estão inseridos no contexto de agilidade e do não perder tempo no fazer da refeição; são locais bem fixados no centro urbano carioca e atendem àqueles que utilizam parcialmente a hora do almoço para efetivamente almoçar.

\section{ACOMPANHAMENTOS}

De segunda a sexta-feira a lógica das refeições é compatível com a rotina de trabalho, mas, ainda assim, cada dia útil tem as suas especificidades.

A comida também acompanha esta variação dos dias da semana. Todos os restaurantes da pesquisa tinham, além de uma base fixa de opções de comida, variações conforme os dias da semana.

Dessa forma, os dias da semana são exemplos de uma sequência regular: com experiências divididas em cada um dos dias. Nesta sequência regular, cada dia possui uma função diferenciada, pois, segundo Mary Douglas (Douglas 1976), o que confere sentido às especificidade de cada dia está exatamente numa forma de sucessão onde há um ordenamento capaz de qualificar os dias, tanto de acordo com a proximidade com o dia que passou quanto com a proximidade com o dia que vai sucedê-lo.

Se utilizarmos o exemplo da sexta-feira para qualificá-la como um dia diferente da quinta e próximo do sábado, é possível verificar que durante as sextas-feiras as pessoas se permitiam "um pouco mais". Um pouco mais de tempo no almoço, um pouco mais de tempo conversando com os colegas, um pouco mais de dinheiro para gastar, um pouco mais de novidade no cardápio.

Portanto, foi numa sexta-feira em que estava visitando pela primeira vez o restaurante árabe da rua que escolhi para realizar o trabalho de campo, que quatro mulheres com média etária de 30 anos, numa mesa animada, decidiram, segundo uma das entrevistadas, "arriscar uma comida diferente e um restaurante novo, fora da rotina de restaurantes que costumamos frequentar na hora do almoço", reiterando que o melhor dia para fazê-lo era mesmo numa sexta-feira.

Assim como neste depoimento, outras declarações apoiaram esta expectativa diferenciada em relação aos dias da semana. Se alguns deles estão mais próximos do final da semana, a comida e a interação entre os comensais se estabelece com maior comunhão, conforto e possibilidade de experiências inovadoras.

Enquanto os dias que se aproximam do sábado e do domingo têm cardápios como a feijoada e o cozido, "que deixam o dia mais animado", podendo "gastar mais e 
demorar mais para comer", os dias que anunciam que o final de semana ainda não se aproxima têm cardápios com comidas mais "práticas" e menos robustas, consideradas mais leves, fáceis de serem consumidas em menos tempo e que são mais baratas.

A refeição oscila entre um intervalo para se alimentar com comida e repor as forças para o trabalho com um momento de prazer associado ao não-trabalho, definindo as escolhas. Conforme se chega mais perto do final de semana, as escolhas tendem a ser definidas pela proximidade com os momentos de lazer e, nos dias onde não se sente próximo o sábado e o domingo, as escolhas são "menos passionais" com pratos mais distantes daqueles que simbolizam momentos de descanso de tarefas de trabalho.

\subsection{Feijão com arroz}

Há ainda um acompanhamento especial, o prato que é hors concurs, presente em todos os restaurantes, independente de suas características culinárias: o feijão com arroz. Ele está no cardápio de todos os restaurantes e não pode faltar nenhum dia. É uma das formas de manutenção dos hábitos tradicionais na alimentação.

O "feijão com arroz" - expressão popular utilizada para fazer referência a fatos do cotidiano, da rotina brasileira - revela que a possibilidade de combinações de comidas que normalmente não seriam servidas numa mesma refeição e os novos arranjos de ambientes para a hora do almoço não anulam estruturas tradicionais. Ao contrário, trazem conforto à novidade, amenizando a impessoalidade de ambientes. $\mathrm{O}$ prato acrescenta parte do ritual tradicional ${ }^{2}$ da refeição em local onde poderia parecer improvável que isto ocorresse.

Dessa forma, o arroz com feijão foi a grande unanimidade dos restaurantes e, por que não, um dos denominadores comuns desses locais, pois era lembrado por todos, ou mesmo nem citado, pois os entrevistados já subentendiam que ele era único e sempre presente.

Se o feijão com arroz representa a tradição, ele não deixa de ser "um modo de integrar a monitoração da ação com a organização tempo-espacial da comunidade; (...) uma maneira de lidar com o tempo e o espaço, que insere qualquer atividade ou experiência particular dentro da continuidade do passado, presente e futuro, sendo estes por sua vez estruturados por práticas sociais recorrentes" (Giddens 1991:44).

\footnotetext{
${ }^{2} \mathrm{O}$ ritual tradicional brasileiro é "subvertido" pelo tempo de refeição encurtado, a comida "já posta", que fica exposta nos bufês e maneira impessoalizada de servi-lo, já que cada um serve seu prato.
} 
Em outras palavras, a temporalidade cuida de ir reafirmando e re-significando o valor de feijão com arroz na representação das tradições do Brasil. Novos lugares, novas formas de servir o prato se unem à constante reafirmação da importância do prato na mesa do brasileiro.

Sendo a cozinha local de resistência de identidades locais e o arroz com feijão representante da cozinha brasileira, ele se mantém importante ao longo do tempo e acompanha as mudanças nas práticas alimentares que possam ocorrer como uma maneira de provar que modelos vistos como representantes de nossas tradições históricas estão longe de desaparecer.

\subsection{Misturas permitidas}

A possibilidade de misturar arroz com feijão e comidas como massas, sushi, pastéis, esfirras - comidas que convencionalmente não são servidas juntas - num único prato não produz sensação de nojo. Isso é possível porque existem diferenças entre os rituais de separação dos alimentos. Há diferenças entre o que se pode misturar em casa e o que se pode misturar na rua, sem que com isso seja gerada alguma estranheza.

A individualização do prato que fazemos em restaurantes a quilo "liberta" o comensal de convenções tradicionais que limitam quais comidas combinam entre si:

Diferentemente do contexto familiar, no qual as decisões alimentares são em grande parte delegadas à dona de casa, no restaurante de auto-serviço (self-service) o comedor constrói individualmente sua escolha a partir de uma oferta mais ou menos aberta. Para responder aos pedidos de uma clientela diversificada, os profissionais da produção de refeições criam universos de ofertas múltiplos, nos quais a liberdade de escolha para o cliente é ampla (Poulain 2006:58).

Assim, a mistura bem-vinda dos restaurantes representa a maior mobilidade das ruas, enquanto as combinações previsíveis das comidas de casa representam a manutenção da estrutura familiar. Dessa forma, as duas alternativas se equilibram, reforçando as características da casa e da rua. Em outras palavras, estas misturas individuais e não convencionais para os pratos que são feitos e compartilhados em casa são comumente formadas e consumidas nas mesas dos restaurantes a quilo do centro da cidade.

\section{SOBREMESA}


Para enfatizar o modo como as pessoas costumam agir na rua, é preciso entender a diferença através das atitudes reveladas quando se está em casa. Não seria possível entender como alguém reage a situações na rua se não houvesse um local distinto onde ficasse clara a diferença, no caso, a casa.

Em casa, estamos confortavelmente reconhecidos por nossos familiares e amigos, enquanto na rua somos apenas um a mais, que transita por ruas movimentadas, tendo de obedecer a regras que nos surgem pelo caminho, desde as mais simples como placas até as mais sofisticadas como códigos velados de respeito ${ }^{3}$ (DaMatta 1997).

Este anonimato da rua - que assusta, pois ficamos todos iguais, como se saíssemos de casa com nossas roupas e, assim que pisássemos na rua, esta roupa se transformasse em uniforme, sem diferenciação a olho nu - faz parte de nossa rotina. Esse processo de sairmos de casa para enfrentarmos "a selva das ruas" é um processo de todo o dia, ou, pelo menos, de segunda à sexta-feira para a maioria dos trabalhadores. Assim, saímos de uma lógica, a da casa, e seguimos para outra, da rua, apenas com o abrir de uma porta.

Na rua, a diminuição do tempo e a individualização das refeições não parecem assustar, enquanto em casa uma das demonstrações de união da família está no hábito de comerem juntos à mesa, compartilhando da mesma comida. Ou seja, a possibilidade de individualização do prato é bem menor, fica restrita, por exemplo, à maneira como se mistura a comida no prato mas todos comem o mesmo tipo de comida.

Se pensarmos na rua como o "lado moderno da sociedade", esta nova conformação de restaurante bem se encaixaria, pois admite, no caso das refeições feitas na hora do almoço, a possibilidade de interação na hora da refeição com pessoas que não estão no grupo de intimidade dos comensais; permite trajes impessoais que não utilizamos quando estamos fazendo refeições em casa, temas que não são abordados em "ambientes familiares", novas misturas de alimentos, enfim combinações distintas daqueles que aprendemos com as maneiras de estar à mesa quando estamos em família.

Mas, ainda assim, não há uma linha que delimita as relações de casa e de rua de maneira bem definida já que o "lado tradicional" da sociedade, retratado pela figura da

\footnotetext{
${ }^{3}$ A estrutura da casa e da rua não é, no entanto, algo rígido. Há a possibilidade de serem encontradas características tidas como da rua no ambiente da casa e vice-versa. Para DaMatta, além de a casa e a rua se complementarem, elas se envolvem, se misturam.
} 
casa insiste em aparecer em depoimentos que citavam a importância de se "confiar" no local frequentado, no grau de intimidade dos clientes com os funcionários, etc.

O lado tradicional de produzir conforto diante de situações impessoais não foge à regra durante o almoço. Mesmo que esta conformação de restaurante não tenha existido sempre, o que se vê é uma maneira de se adaptar características de encurtamento de tempo de comer, pratos já prontos para serem servidos pelo próprio indivíduo e pesagem da comida com situações de maior interação do cliente com o local.

"A tradição não é inteiramente estática, porque ela tem que ser reinventada a cada nova geração conforme assume sua herança social dos precedentes" (DaMatta 1997:15). Esta afirmação bem se encaixa nos depoimentos que traduzem estas relações de conforto mesmo fora de casa. Como as relações com o que se entende como sendo tradicional são relações constantemente reformadas e reexaminadas, elas podem surgir em locais novos, sob novas conformações do que seria o tradicional.

Portanto, não podemos dizer que há uma oposição severa entre as duas estruturas da casa e da rua. Pelo contrário, a possibilidade de interação entre ambas torna mais rica a interpretação destes locais. Nesse sentido, há tanto marcas de impessoalidade, como as ideias acerca de "tempo", quanto marcas de pessoalidade, como a intimidade com o restaurante, por exemplo.

\section{UM CAFEZINHO...}

Os restaurantes a quilo que se situam no centro da cidade do Rio de Janeiro mostram que, por mais que existiam outros parecidos em outras cidades ou países, existem também suas especificidades locais. Até mesmo lanchonetes de grandes redes como o McDonalds, "têm significados diferentes em lugares diferentes" (Burke 2007:05).

Apesar de haver pontos de convergência entre os países, isto não uniformiza todos. O olhar é singular. Portanto, por mais que existam características comuns, como a rapidez com que as refeições são feitas - fato que é comum a diversos tipos de estabelecimentos em todo o país e, porque não, em todo o mundo -, há modos locais de utilização dos ambientes.

Voltando ao caso dos restaurantes a quilo, há sim características que são encontradas em restaurantes espalhados por diversas partes do mundo. Mas, ao mesmo 
tempo, há alimentos como o arroz e feijão, que fazem parte do que se chama de "comida tradicional do brasileiro", que se mantem como prato obrigatório em todos os locais, desde os mais simples até os mais sofisticados, passando por restaurantes que têm como especialidade saladas ou comidas árabes.

"Mesmo na mais modernizada das sociedades, a tradição continua a desempenhar um papel" (Giddens 1991:44). Com isso, ao mesmo tempo em que os alimentos que são tidos como característicos de certo local se descolam e são distribuídos em escala mundial, eles também convivem com especificidades locais, na maneira como são servidos, na mistura feita com outros alimentos, na sociabilidade que envolve seu consumo.

Isto quer dizer que os particularismos nacionais ainda são muito fortes e que uma cultura mundializada não implica o aniquilamento das outras manifestações culturais; ela convive e se alimenta delas. Quando se encontram formas de padronização, acham-se também formas que traduzem a manutenção de um padrão cultural; não é “a uniformização de todos” (Ortiz 1994:33).

"Hoje existe uma visão mais complexa entre tradição e modernidade" (Canclini 1997:23), não são definições que não se tocam, há um hibridismo. O que aconteceu com as sociedades modernas foi uma transformação delas em algo muito mais complexo. $\mathrm{O}$ leque de relações, informações, fluxos de trabalho, acordos globais acabou por transformá-las, fazendo surgir novidades nas relações do sujeito com o mundo.

Reforço o argumento da importância de ambas as manifestações - tanto as mundiais quanto as locais - pois elas fazem por recriar os dois processos. O que é entendido como moderno e como tradicional é duplamente reinventado a partir da constituição de novos locais onde se possa verificar o que são atividades que se revelam como apontando para quesitos de novidade e para quesitos de permanência. "O local não está necessariamente em contradição com o global, pelo contrario, encontram-se interligados" (Ortiz 1994:30).

Pensando neste aspecto de interação do "novo" e do "velho" em novos ambientes sociais - no caso, os restaurantes do tipo a quilo -, não há como entender o perfil destes estabelecimentos comparando-os com formas antigas de locais que usavam uma ou outra característica semelhante a este. Seria uma simplificação da tarefa de interpretá-los.

O contexto atual no qual estão inseridos demonstra que por mais que haja semelhanças com outros locais que servem refeições em todo o mundo ou até mesmo 
em outras épocas, surgem diferenças reveladoras de novas transformações e de novos arranjos, novas formas de mesclar elementos modernos e tradicionais. Assim o que se entende como sendo novidade e antiguidade se renova e se interpreta de maneira peculiar no uso dos locais no momento das refeições diárias.

\section{6. ... A CONTA}

A "novidade trazida pelos restaurantes a quilo" criou uma nova forma de interagir com a comida, os comensais, a hora da refeição e tudo o mais que envolva o ritual de alimentação. Podemos nestes espaços identificar características da mundialização e, ao mesmo tempo, valores e costumes nacionais que continuam firmes no nosso cotidiano.

No caso brasileiro - neste momento representado pelos restaurantes a quilo -, traços da identidade cultural nacional não são sobrepostos por padrões alimentares estrangeiros. Ambos acabam por se misturar e por reinventar sua forma de atuação na prática cotidiana.

\section{REFERÊNCIAS BIBLIOGRÁFICAS}

BARBOSA, L. N. de H. "Porque hoje é sábado... Um estudo das representações dos dias da semana” In: Boletim do Museu Nacional, n. ${ }^{\circ}$ 49, Rio de Janeiro, 1984.

BURKE, P. "MC2", In: Caderno Mais, Folha de São Paulo, São Paulo, 15 /04/ 2007, p. 05.

CANCLINI, N. Culturas Híbridas: Estratégias para entrar e sair da Modernidade, São Paulo, Edusp, 1997.

CARNEIRO, H. Comida e Sociedade - Uma história da alimentação, Rio de Janeiro: Campus, 2003.

DAMATTA, R. Relativizando, Rio de Janeiro, Rocco, 1987. . O que faz do brasil, Brasil? , Rio de Janeiro, Rocco, 1991. . A Casa e a Rua. Rio de Janeiro: Rocco, 1997.

DOUGLAS, M. Pureza e Perigo. São Paulo, Perspectiva, 1976.

GIDDENS. A. As conseqüências da modernidade. São Paulo, UNESP, 1991.

LESSA, C. "Trajetórias da cidade moderna". In: Rio de Janeiro: panorama sociocultural, Rio de Janeiro, Editora Rio, 2004. 
O Rio de todos os Brasis: uma reflexão em busca de auto-estima, Rio de Janeiro, Record, 2005.

ORTIZ, R. Mundialização e Cultura, São Paulo, Editora Brasiliense, 1994.

POULAIN, J.P. Sociologias da Alimentação, Florianópolis, Editora da UFSC, 2006.

Artigo recebido: 2/12/09

Artigo aprovado: 10/12/09 